\title{
New genus and species of sisyrids (Insecta, Neuroptera) from the Late Cretaceous Myanmar amber
}

\author{
Qiang Yang ${ }^{1,2,3}$, Chaofan Shi ${ }^{2,4}$, Dong Ren², Yongjie Wang ${ }^{2}$, Hong Pang' \\ I State Key Laboratory of Biocontrol, Key Laboratory of Biodiversity Dynamics and Conservation of Guangdong \\ Higher Education Institute, Ecology and Evolution, School of Life Sciences, Sun Yat-sen University, Guangzhou \\ 510275, PR China 2 College of Life Sciences, Capital Normal University, Xisanhuanbeilu 105, Haidian \\ District, Beijing 100048, PR China 3 Geoscience Museum, Hebei GEO University, 136 Huaiandonglu, Shi- \\ jiazhuang, 050031, PR China 4 School of Earth Sciences and Engineering, Sun Yat-sen University, Guangzhou \\ 510275, PR China
}

Corresponding authors: Hong Pang (lsshpang@mail.sysu.edu.cn); YongjieWang (wangyjosmy@gmail.com)

Academic editor: Jes Rust | Received 16 November 2017 | Accepted 30 January 2018 | Published 23 February 2018

http://zoobank.org/5F9A8963-8F78-4DB7-895D-8E8A88D1F20A

Citation: Yang Q, Shi C, Ren D, Wang Y, Pang H (2018) New genus and species of sisyrids (Insecta, Neuroptera) from the Late Cretaceous Myanmar amber. ZooKeys 739: 151-158. https://doi.org/10.3897/zookeys.739.22310

\begin{abstract}
A new genus and species of Sisyridae, Stictosisyra pennyi gen. et sp. n., is described from the Late Cretaceous (earliest Cenomanian/late Albian) Myanmar amber. It can be easily distinguished from other sisyrids genera by the configuration of wing venation such as forewing with four ra-rp crossveins, $\mathrm{M}$ forked distal to the separation of RP1, CuA pectinate and CuP simple; hind wing $1 \mathrm{r}-\mathrm{m}$ long and sinuous. Besides, the newly documented spongillaflies bore distinct, irregularly distributed spots on the forewings.
\end{abstract}

\section{Keywords}

spongillaflies, Burmese, Mesozoic, fossil, color spots

\section{Introduction}

Sisyridae is a small and one of the most ancient family of Neuroptera, comprising about 70 extant species (Oswald 2015) assigned to four genera (Sisyra Burmeister, 1839, Sisyrina Banks, 1939, Sisyborina Monserrat, 1981, and Climacia McLachlan, 1869). Sisyra is cosmopolitan. Climacia are distributed in the Nearctic and Neotropics. Sisyrina are in the Afrotropics, Indomalaya and Australasia. Sisyborina is restricted to the Afrotropics (Os-

Copyright Qiang Yang et al. This is an open access article distributed under the terms of the Creative Commons Attribution License (CC BY 4.0), which permits unrestricted use, distribution, and reproduction in any medium, provided the original author and source are credited. 
wald 2015). The fossil record of Sisyridae is very rare, dating back to the Late Cretaceous. To date, three extinct genera with six species have been described, all from Eurasia: Paleosisyra eocenica Nel, Menier,Waller, Hodebert \& de Ploëg, 2003; P. electrobaltica Wichard, Gröhn \& Seredszus, 2009; P. minor Wichard, Wedmann \& Weiterschan, 2016; Prosisyrina sukachevae Perkovsky \& Makarkin, 2015; P. sphinga Makarkin \& Perkovsky, 2016; and Paradoxosisyra groehni Makarkin, 2016. Also Perkovsky and Makarkin (2016) give a list of known fossil Sisyridae including undetermined species.

Here, we describe a new genus and species, Stictosisyra pennyi gen. et sp. n., of Sisyridae, from the lowermost Cenomanian Myanmar amber. This is the second species of the family in this locality. The former described species, Paradoxosisyra groehni, possessing relatively long, siphonate mouthparts, is unique among Sisyridae. Based on this species, the extinct subfamily Paradoxosisyrinae was erected. Paradoxosisyrinae are common in Burmese amber, with tens of specimens found (pers. obs.). The new genus and species described here does not belong to Paradoxosisyrinae, but shares more characters in common with the extant Sisyridae.

\section{Material and methods}

This study is based on one male specimen from Myanmar amber. The amber pieces were collected in the Hukawng Valley (the state of Kachin in northern Myanmar). A map of the Hukawng Valley is given by Grimaldi et al. (2002, fig. 1). The volcaniclastic matrix of the amber is estimated to be $-98.79 \pm 0.62$ million years old, i.e., near the Albian/Cenomanian (Early/Late Cretaceous) boundary (Shi et al. 2012). The biological inclusions of Myanmar amber represent a sample of a tropical forest community in equatorial southeastern Asia at $\sim 12 \_N$ paleolatitude (Grimaldi et al. 2002; Poinar et al. 2008; Zhang et al. 2017; Ren et al. 2017). The specimen is housed in the collection of the Key Laboratory of Insect Evolution \& Environmental Changes, College of Life Sciences, Capital Normal University, Beijing, China (CNUB; Dong Ren, Curator). The specimen was examined using a Zeiss Discovery V20 stereomicroscope and photographed with an AxioCam HRc digital camera attached to the Zeiss Discovery V20 stereomicroscope (both instruments Carl Zeiss Light Microscopy, Göttingen, Germany). Line drawings were prepared with the CorelDraw X4 graphics software and with the aid of Adobe Photoshop CC.

Venation terminology in general follows Kukalová-Peck and Lawrence (2004) as interpreted by Yang et al. (2012, 2014). Terminological details of venation (e.g., spaces, veinlets, traces) follows Oswald (1993). Crossveins are designated after the longitudinal veins with which they connect and are numbered in sequence from the wing base, e.g., $1 \mathrm{r}-\mathrm{m}$, a crossvein connecting $\mathrm{R} / \mathrm{RP}$ and $\mathrm{M} / \mathrm{MA}$ in the first series.

Abbreviations: AA1-AA3, first to third anterior anal vein; $\mathrm{CuA}$, anterior cubitus; $\mathrm{CuP}$, posterior cubitus; MA and MP, anterior and posterior branches of media; RA, anterior radius; RP, posterior sector; RP1, proximal-most branch of RP; RP2, branch of RP distad RP1; ScA, subcosta anterior; ScP, subcosta posterior. 


\section{Systematic paleontology}

Class Insecta Linnaeus, 1758

Order Neuroptera Linnaeus, 1758

Family Sisyridae Banks, 1905

Genus Stictosisyra Yang, Shi, Wang \& Pang, gen. n.

http://zoobank.org/DD782A02-2AA7-4578-A18C-10F8CBE41B9F

Type and only species. Stictosisyra pennyi Yang, Shi, Wang \& Pang, gen. et sp. n.

Etymology. The generic name is a combination of stict- (Greek, meaning speckled, flecky), in reference to the irregular brown spots distributed on the forewings; and Sisyra, type genus of the family. Gender feminine.

Diagnosis. Forewing with four ra-rp crossveins, $\mathrm{M}$ forked distal to the separation of RP1, CuA pectinately branched, CuA branches simple, CuP simple. Forewing with irregularly distributed spots over whole wing. Hind wing with one ra-rp, $1 \mathrm{r}-\mathrm{m}$ very long and sinuous, connected stem of RP and $\mathrm{M}$.

\section{Stictosisyra pennyi Yang, Shi, Wang \& Pang, sp. n.} http://zoobank.org/C0203F16-A571-4B38-AD51-61593094D8F8

Fig 1-3

Etymology. The specific epithet is in memory of Dr. Norman D. Penny (1946-2016), in recognition of his great contribution to the lacewing study. The first two authors were impressed by his kindles and generosity when visiting the California Academy of Sciences in 2016.

Diagnosis. As for the genus.

Holotype. CNU-NEU-MA2017006, assumed male, nearly complete and well preserved specimen.

Locality and horizon. Hukawng Valley, Kachin State, northern Myanmar; lowermost Cenomanian, Upper Cretaceous.

Description. Holotype CNU-NEU-MA2017006. Total body length $2.9 \mathrm{~mm}$. Head and body with numerous scattered, fine setae; head about as wide as long. Compound eyes large. Antenna moniliform, with scattered setae all over; scape nearly 2 times as long as wide, slightly thicker than flagellum; pedicel elongate, about 2 times as long as wide; flagellum with about 25 flagellomeres, first flagellomere longer than others, about as long as pedicel, and last one elongate, about 2.5 times as long as other flagellomeres, apically tapered. Pronotum narrower than head, twice as long as wide; pro-, meso- and metanotum with scattered, fine, long setae. Legs relatively long and slender, with numerous short setae intermixed with long setae. Foreleg: coxa elongated; femur long and slender; tibia nearly as long as femur; basitarsus nearly thrice as long as second tarsomere, the last four tarsomeres of same length. 


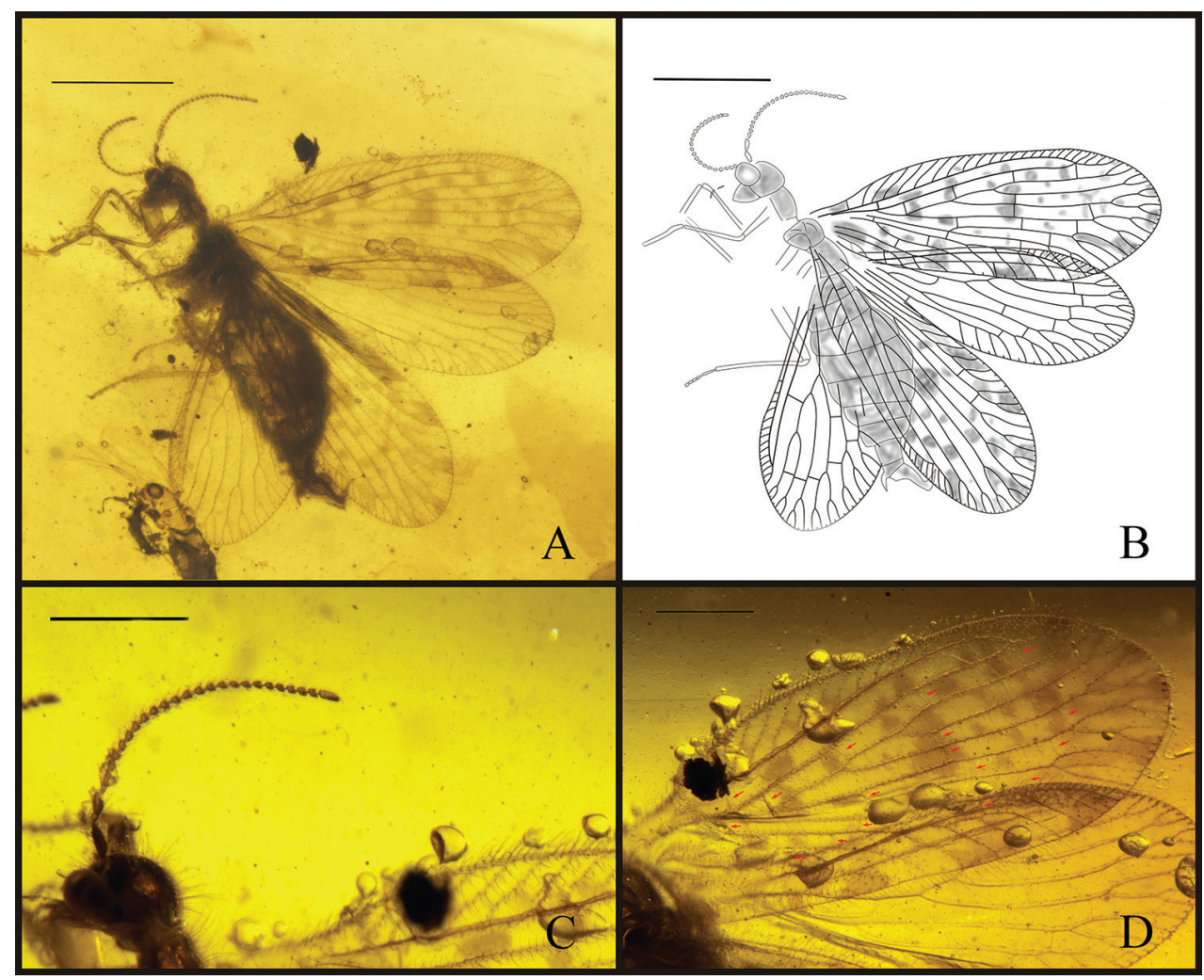

Figure I. Stictosisyra pennyi gen. et sp. n., holotype CNU-NEU-MA2017006. A photograph of holotype $\mathbf{B}$ line drawing of holotype $\mathbf{C}$ detail photograph of antenna $\mathbf{D}$ forewing with a squint view, red arrow shows the distribution of crossveins. Scale bars: $1 \mathrm{~mm}(\mathbf{A}, \mathbf{B}) ; 0.5 \mathrm{~mm}(\mathbf{C}, \mathbf{D})$.

Mid-, hind legs poorly preserved. Abdomen nine segments, with scattered short setae.

Forewing length $3.0 \mathrm{~mm}$, width $1.1 \mathrm{~mm}$ (right forewing); elongated ovoid, apex rounded, with dense relatively short setae on veins and longer setae on margins; membrane with fuscous spots over whole wing; trichosors prominent along entire wing margin. Humeral vein short and simple, not recurrent, perpendicular to ScP; presumable ScA not detected; costal space narrow; subcostal veinlets simple, not forked, pterostigma not present. ScP and RA fused distally, entering margin before wing apex. Only one sc-r present. Four ra-rp crossveins, distalmost ra-rp crossvein located at fusion of $\mathrm{ScP}$ and RA; RP separated from RA just proximal to sc-r, with three branches. RP1, RP2 configuration similarly, dichotomously forked, RP3 with a distal fork, about two crossveins between RP1, RP2, and one crossvein between RP2, RP3. M divided into MA and $\mathrm{MP}$ at $2 \mathrm{~m}-\mathrm{cu}$, far from separation of RP1 from RP stem, one ma-mp crossvein present; MA distally forked twice, MP pectinately forked, with two branches distally; three $\mathrm{r}-\mathrm{m}$ crossveins between $\mathrm{RP}$ and $\mathrm{M}$; $\mathrm{Cu}$ divided into $\mathrm{CuA}$ and $\mathrm{CuP}$ near wing base at level of $\mathrm{RP}$ origin, three $\mathrm{m}$-cu crossveins; $\mathrm{CuA}$ pectinately forked, with three (right forewing) or 


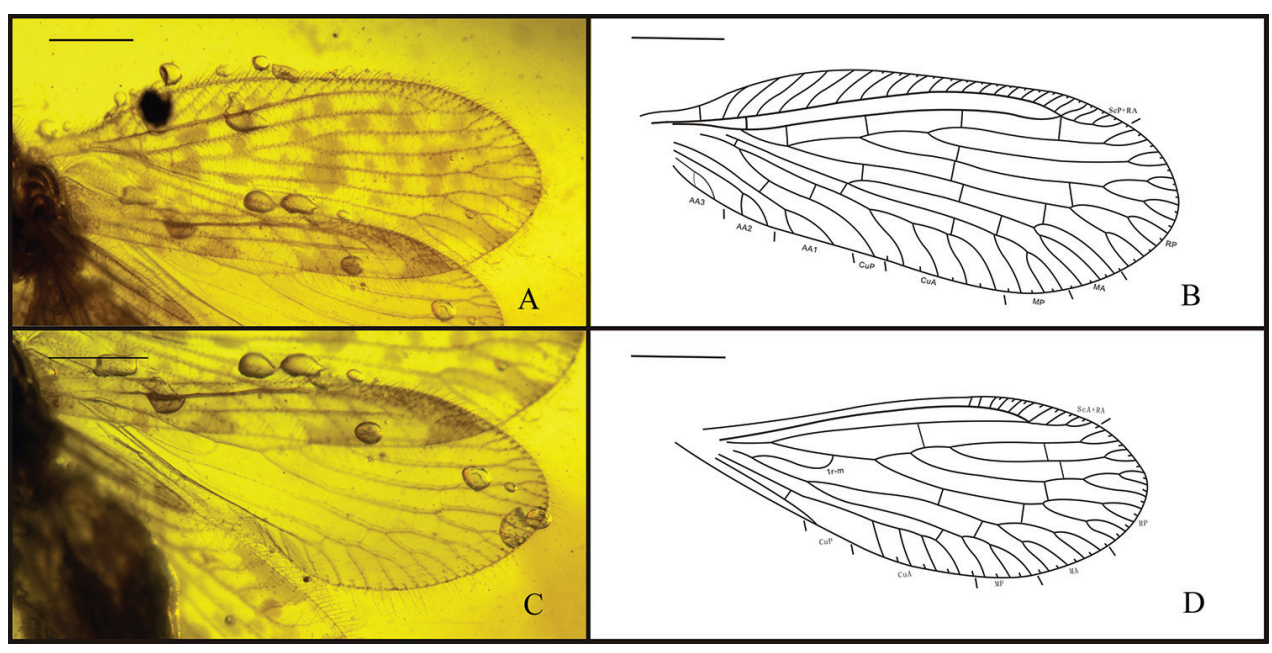

Figure 2. Stictosisyra pennyi gen. et sp. n., holotype CNU-NEU-MA2017006. A photograph of forewing $\mathbf{B}$ line drawing of forewing $\mathbf{C}$ photograph of hind wing $\mathbf{D}$ line drawing of hind wing. Scale bars: $0.5 \mathrm{~mm}$.

four (left forewing) simple branches distal to $2 \mathrm{~m}$-cu; $\mathrm{CuP}$ simple, one crossvein between $\mathrm{CuA}, \mathrm{CuP}$; only one $2 \mathrm{cu}-\mathrm{aa}$ visible; AA1, AA2, AA3 configuration similarly, each with a distal fork, no crossveins detected between AA region.

Hind wing elongate, slightly smaller than forewing, length $2.5 \mathrm{~mm}$, width $0.9 \mathrm{~mm}$ (right hind wing). Trichosors prominent along entire wing margin. No color spots on wing or along margin. Costal space narrow, distally dilated, especially distad fusion of ScP and RA. Subcostal veinlets simple, sparsely spaced, pterostigma not present. Subcostal space broader than costal space, basally narrowed; no crossvein detected. ScP, $\mathrm{RA}$ fused distally. $\mathrm{ScP}+\mathrm{RA}$ entering wing margin before apex, with three simple distal veinlets. RA space wider than subcostal space, with one crossveins located between origin of RP2 and RP3. RP originated near wing base, with three branches originating far from wing base, each forked distally. Stem of RP and RP3 just with a distal fork; RP1 dichomously forked, RP2 forked twice distally. Three crossvein between RP region; three $\mathrm{r}-\mathrm{m}$ crossveins between RP and $\mathrm{M}$, basal $1 \mathrm{r}-\mathrm{m}$ between stem $\mathrm{R}$ and $\mathrm{M}$ long and strongly sinuous. $\mathrm{M}$ forked distad origin of RP and proximal to origin of RP1. MA dichotomously branched distally; MP forked twice distally. Only one crossvein between $\mathrm{MA}$ and MP. CuA long, pectinately branched with about three simple branches; $\mathrm{CuP}$ long and simple. One crossvein between $\mathrm{M}$ and $\mathrm{Cu}$; one crossvein visible between $\mathrm{CuA}$ and $\mathrm{CuP}$. Anal veins not preserved.

Remarks. Stictosisyra gen. n. is different from other fossil sisyrids genera in the following characters: 1) without long siphonate mouthparts (Paradoxosisyra with long siphonate mouthparts); 2) forewing with four ra-rp (Paleosisyra eocenica with two, $P$. electrobaltica and $P$. minor with three); 3) hind wing $\mathrm{ScP}$ and RA fused before entering the margin, and with one ra-rp (Prosisyrina hind wing ScP and RA terminate separately, with two ra-rp). 


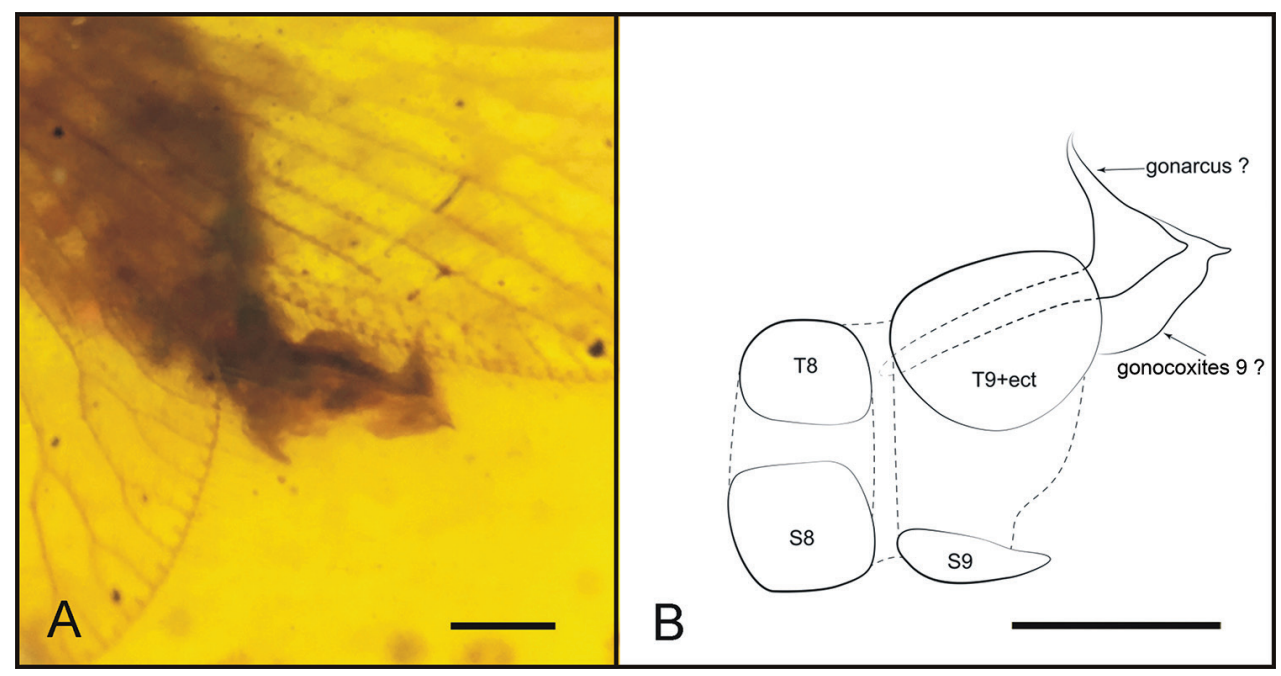

Figure 3. Stictosisyra pennyi gen. et sp. n., holotype CNU-NEU-MA2017006. A photograph of genitalia B line drawing of genitalia (T: tergite; S: sternite; ect: ectoproct). Scale bars: $0.2 \mathrm{~mm}$.

Comments. Male genitalia. The genitalia of the holotype was not well preserved in the amber; furthermore, the morphology is quite different from that of other sisyrids. Herein we tentatively assume the specimen to be a male based on the morphology of abdomen, especially of the terminalia, and the preserved posture. The genitalia are interpreted as follows: tergite 9 and ectoproct fused; sternite 9 shorter than tergite $9+$ ectoproct; gonarcus extend beyond tergite $9+$ ectoproct, otherwise, may be caused by posteriorly incomplete preservation of tergite 9+ectoproct; gonarcus narrowly arched medially, with two arms ventrally and afterwards anteriorly extended; each arm with a tiny extension pointed posteriorly; large, and almost whole external gonocoxites 9, connected with gonarcus.

\section{Acknowledgements}

We appreciate the valuable comments and useful suggestions on our manuscript from the editor (Jes Rust) and reviewer (Vladimir N. Makarkin). This research was funded by grants from the Basic Work Special Project of the National Ministry of Science and Technology of China (2013FY111500), the specimen platform of China, teaching specimens sub-platform, Web, http://mnh.scu.edu.cn/, National Natural Science Foundation of China (grant nos. 41602014, 31501881, 31730087), China Postdoctoral Science Foundation (grant no. 2016M592570), Natural Science Foundation of Hebei Province (grant no. C2015403012), Basal Research Fund of SYSU (grant nos. 32110-41030349), Program for Changjiang Scholars and Innovative Research Team in University (grant no. IRT-17R75) and Support Project of High-level Teachers in Beijing Municipal Universities (IDHT20180518). 


\section{References}

Banks N (1905) A revision of the Nearctic Hemerobiidae. Transactions of the American Entomological Society 32: 21-51.

Banks N (1939) New genera and species of neuropteroid insects. Bulletin of the Museum of Comparative Zoology 85: 439-504.

Burmeister HCC (1839) Handbuch der Entomologie. Zweiter Band. Besondere Entomologie. Zweite Abtheilung. Kaukerfe. Gymnognatha. (Zweite Hälfte; vulgo Neuroptera). Theodor Johann Christian Friedrich Enslin, Berlin, 757-1050.

Kukalová-Peck J, Lawrence JF (2004) Relationships among coleopteran suborders and major endoneopteran lineages: evidence from hind wing characters. European Journal of Entomology 101: 95-144. https://doi.org/10.14411/eje.2004.018

Linnaeus C (1758) Systema naturae per regna tria naturae secundum classes, ordines, genera, species, cum characteribus, differentiis, synonymis, locis $\left(10^{\text {th }} \mathrm{edn}\right)$. Vol. 1. Salvii, Holmiae, 824 pp.

Makarkin VN (2016) Enormously long, siphonate mouthparts of a new, oldest known spongillafly (Neuroptera: Sisyridae) from Burmese amber imply nectarivory or hematophagy. Cretaceous Research 65: 126-137. https://doi.org/10.1016/j.cretres.2016.04.007

Makarkin VN, Perkovsky EE (2016) An interesting new species of Sisyridae (Neuroptera) from the Upper Cretaceous Taimyr amber. Cretaceous Research 63: 171-176. https://doi. org/10.1016/j.cretres.2016.03.010

McLachlan R (1869) New species, \&c., of Hemerobiina; with synonymic notes (first series). Entomologists Monthly Magazine 6: 21-27.

Monserrat VJ (1981) Sobre los Sisíridos de la Regi_on Oriental (Neuroptera, Planipennia, Sisyridae). EOS: Revista Espanola de Entomologia 57: 165-186.

Nel A, Menier JJ, Waller A, Hodebert G, de Ploëg G (2003) New fossil spongillaflies from the lowermost Eocene amber of France (Insecta, Neuroptera, Sisyridae). Geodiversitas 25: 109-117.

Oswald JD (1993) Revision and cladistic analysis of the world genera of the family Hemerobiidae (Insecta: Neuroptera). Journal of the New York Entomological Society 101: 143-299.

Oswald JD (2015) Neuropterida Species of the World. Version 4.0. http://lacewing.tamu.edu/ SpeciesCatalog/Main [accessed 2018.01.07]

Perkovsky EE, Makarkin VN (2015) First confirmation of spongilla-flies (Neuroptera: Sisyridae) from the Cretaceous. Cretaceous Research 56: 363-371. https://doi.org/10.1016/j. cretres.2015.06.003

Poinar Jr GO, Buckley R, Brown AE (2008) The secrets of Burmite amber. MAPS Digest 20: $20-29$.

Ren MY, Zhang WT, Shih CK, Ren D (2017) A new earwig (Dermaptera: Pygidicranidae) from the Upper Cretaceous Myanmar amber. Cretaceous Research 74: 137-141. https:// doi.org/10.1016/j.cretres.2017.02.012

Shi GH, Grimaldi DA, Harlow GE, Wang J, Wang J, Yang MC, Lei WY, Li QL, Li XH (2012) Age constraint on Burmese amber based on UePb dating of zircons. Cretaceous Research 37: 155-163. https://doi.org/10.1016/j.cretres.2012.03.014 
Wichard W, Gröhn C, Seredszus F (2009) Aquatic Insects in Baltic Amber. Wasserinsekten im Baltischen Bernstein. Verlag Kessel, Remagen, 336 pp.

Wichard W, Wedmann S, Weiterschan T (2016) Spongillaflies (Neuroptera, Sisyridae) in Baltic amber. Zootaxa 4158(1): 117-125. https://doi.org/10.11646/zootaxa.4158.1.7

Yang Q, Makarkin VN, Ren D (2014) Two new species of Kalligramma Walther (Neuroptera: Kalligrammatidae) from the Middle Jurassic of China. Annals of the Entomological Society of America 107: 917-925. https://doi.org/10.1603/AN14032

Yang Q, Makarkin VN, Winterton SL, Khramov AV, Ren D (2012) A remarkable new family of Jurassic insects (Neuroptera) with primitive wing venation and its phylogenetic position in Neuropterida. PLoS ONE 7(9): e44762. https://doi.org/10.1371/journal.pone.0044762

Zhang WT, Li H, Shih CK, Zhang AB, Ren D (2017) Phylogenetic analyses with four new Cretaceous bristletails reveal inter-relationships of Archaeognatha and Gondwana origin of Meinertellidae. Cladistics 1-23. https://doi.org/10.1111/cla.12212 